\title{
Retraction Note: Coastline soil loss rate and coastal trade English vocabulary translation based on GIS system
}

\author{
Yifan Zhang ${ }^{1} \cdot$ Di Wang $^{2}$ \\ Published online: 3 November 2021 \\ (c) Saudi Society for Geosciences 2021
}

Retraction Note to: Arabian Journal of Geosciences (2021) 14: 1664 https://doi.org/10.1007/s12517-021-08058-3

The Editor-in-Chief and the Publisher have retracted this article because the content of this article is nonsensical. The peer review process was not carried out in accordance with the Publisher's peer review policy. The authors have not responded to correspondence regarding this retraction.

Publisher's note Springer Nature remains neutral with regard to jurisdictional claims in published maps and institutional affiliations.

The original article can be found online at https://doi.org/10.1007/ s12517-021-08058-3.

Yifan Zhang

agnesdw@163.com

1 School of Foreign Languages, Huazhong University of Science and Technology, Wuhan 430074, China

2 School of Foreign Languages, Wenhua College, Wuhan 430074, China 